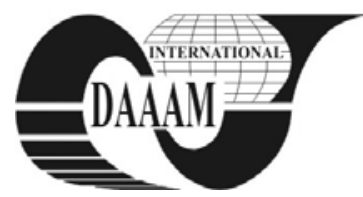

\title{
THE IMPACT OF HIGHLY VARYING ORDER SIZES ON A CONWIP CONTROLLED PRODUCTION LINE
}

\author{
LUFTENSTEINER, F[ranz] \& STOPPER, M[arkus]
}

\begin{abstract}
Customer requirements are demanding, especially regarding short delivery lead times, broad product variety, high service level and low prices. Manufacturing companies are constantly forced to improve cost effectiveness. Appropriate production planning and control systems (e.g. CONWIP) can help to achieve this goal. The CONWIP parameter "maximum WIP-level" is being discussed in regard to a continuous flow production with highly varying customer order sizes. It is shown that under particular manufacturing conditions this parameter should not be used. An alternative strategy is presented.
\end{abstract}

Key words: make to order, work in process, CONWIP

\section{INTRODUCTION}

Companies are facing a strong and global competition on the one hand and customers with individual and different needs on the other hand. The challenge is to meet the customer requirements and to run a profitable and sustainable business. Customers demand short delivery times, a high service level and a broad product variety.

Effective production planning and control systems (PPS) are those which produce the right parts, at the right time, at competitive costs (Spearman et al., 1990). Thus, companies have to find the appropriate PPS to the meet the objectives as mentioned above.

In this paper we focus on a production environment with a large number of product variants and highly varying order sizes, assuming a continuous flow production with a production and assembling line including 3 workstations with the first as a distinct bottleneck. In practice the customer orders a certain amount of one or more product variants. Goods are expected to be delivered at a certain due date.

We further assume that the production lead time is smaller than the delivery lead time so that we face a pure Make-toOrder scenario. Furthermore we take a backlog list as a given. The backlog list only summarizes customer orders, so there are no orders based on a forecast.

This paper discusses the impact of highly varying order sizes on the WIP-level parameter of a PPS called CONWIP.

\section{CONWIP}

CONWIP (CONstant Work in Process) is a production planning and control system (PPS), which was introduced by Spearman et al. in 1990. It appears to share the benefits of kanban (pull-based) while being applicable to a wider variety of production environments. Additionally CONWIP integrates the customer orientation of the push-based material requirements planning (Spearman et al., 1990).

The main idea of CONWIP is to maintain a maximum constant work in process. This is usually done by using cards (or electronic signals) which are assigned to a job order at the beginning of the line. At the end of the production line the card is released into a queue and can be assigned to the next job order. A job order can only be processed with a card present so that every job is authorized for processing (Spearman et al., 1990). Fig. 1 shows a CONWIP schematic. As soon as a card, which can be matched with an order from the backlog list is available in the queue, raw material is released from inventory for the first work station (WS1). After production is finished products are stored in finished goods inventory (FGI).

According to Spearman et al., 1990, products are moved through the production line in a standard container. Job orders have to be combined so that each container includes nearly the same amount of work. Cards are being attached to a standard container and are assigned to the production line.

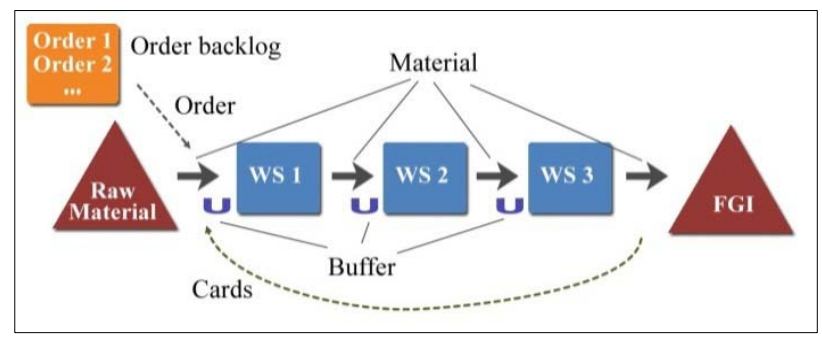

Fig. 1. CONWIP schematic (Source: Modified from Spearman et al., 1990)

There are several decisions to be made in order to establish a CONWIP system (Framinan et al., 2003):

- Number of cards operating the system

The number of cards determines the maximum quantity of containers being processed by the production line.

- The production quota

The production quota is the target production quantity for a period (Spearman et al., 1990).

- Maximum amount of work

The quantity of work in each container in combination with the number of cards determines the maximum amount of work being processed by the production line at the same time.

- Capacity shortage trigger

This trigger indicates that additional capacity must be utilized for a certain period (Spearman et al., 1990). Furthermore excess capacity is being indicated as well.

- Forecasting the backlog list

According to our assumption the backlog list is based on direct customer orders.

- Sequencing the jobs in the system

The original rule how to sort jobs in the intermediate buffers presented by Spearman et al., 1990, is FCFS (First Come First Served).

Research shows that in a continuous flow production CONWIP offers a higher service level performance in combination with lower inventory levels compared to kanban (Altendorfer \& Jodlbauer, 2007). Furthermore CONWIP has a lower number of 
parameters that have to be adjusted than e.g. MRP or kanban (Jodlbauer \& Huber, 2008).

\section{OPERATION OF CONWIP}

In practice a backlog list is maintained by an operator who is allowed to rearrange jobs in the backlog list. Further research (Altendorfer \& Jodlbauer, 2007) has resulted in a job order list in compliance with certain rules.

Instead of determining a production quota for a certain period, the authors (Altendorfer \& Jodlbauer, 2007) suggest to define a work-ahead-window. The work-ahead-window is a time period, which avoids the production of goods with due dates that are too far in the future.

\subsection{Job order list}

The job order list consists of four sections, depending on the different status of job orders (Altendorfer \& Jodlbauer, 2007):

\section{- Status 1: Not yet released for scheduling}

Job orders with due dates beyond the work-ahead-window.

\section{- Status 2: Released for scheduling}

Job orders with due dates inside of the work-aheadwindow. These jobs are being sequenced according to their due dates or other appropriate rules.

\section{- Status 3: Released for production}

These job orders have been dispatched to the first work center. Jobs in production are being sequenced according to certain rules, e.g. "First Come First Served” (FCFS).

- Status 4: Finished

These jobs have been finished and are subject to delivery to the customer at the specified due date.

To determine "work-in-process" the number of cards attached to a container and the amount of work per container have to be multiplied. Assuming the same amount of work in each container the maximum WIP-level is set by the number of cards. When operating CONWIP with a job order list as mentioned above we have to sum up the amount of work in status 3 and 4 only. New jobs can only enter the production system with a card present, which means that the WIP-level including the new job has to be smaller than the maximum WIP-level defined.

\subsection{Setting a maximum WIP-level}

At first we have to decide how to measure the WIP-level in a certain environment. According to Altendorfer et al., 2010, WIP can be measured in pieces, if the production lead time is nearly the same for each product variant.

Setting the maximum WIP-level is subject of ongoing research. Spearman et al., 1990, and Altendorfer \& Jodlbauer, 2007, suggest to start with a higher level and to gradually lower it over time. An overvalued WIP-level leads to higher inventory levels than required. Setting the WIP-level too low negatively influences the service level.

In this paper we focus on highly varying order sizes. Every order moves through the production and assembling line as a single batch. Batches are now corresponding to the container principle as mentioned above. However, the quantity of work (pieces) per batch highly varies according to the customer orders. For this reason the WIP-level varies as well.

We assume a situation with high utilization of the production line and a maximum WIP-level set. A large customer order (Status 2) is the next one to be released for production. As long as the WIP-level including the large order is higher than the maximum WIP-level the order will not be released for production.

It is obvious that under certain circumstances the first workstation (distinct bottleneck) or even further workstations could unnecessarily run out of work. Therefore the output of the production line is not as high as possible.
One of the results could be an adverse impact on the customer due dates in the form of a delivery delay.

\subsection{Operating CONWIP without a maximum WIP-level}

To avoid negative impacts, there exist two different strategies. The first one is to limit order quantities if possible. In this case the maximum WIP-level can be set as suggested by Spearman et al., 1990.

The second possibility is not to set a maximum WIP-level at all. If there is no maximum WIP-level another rule must exist to limit the job orders released for production: The operator has to release (from status 2 to status 3) as many job orders as necessary so that the first workstation (bottleneck) is always busy.

All job orders with status 2 (Released for scheduling) fulfill the restrictions of the work-ahead-window. It is the responsibility of the operator to release the appropriate amount of job orders for production. In relation to a "standard"CONWIP implementation the operater bears much more responsibility for the very functioning of the production line.

\section{CONCLUSION}

Customer requirements are demanding: Short delivery times, a high service level and a broad product variety in combination with low prices. Production companies have to improve cost effectiveness to stay in business. Appropriate production planning and control systems (PPS) contribute to a contionous improvement.

This paper describes the CONWIP (CONstant Work In Process) control system and particularly the setting of the maximum WIP-level parameter in a certain environment. The CONWIP idea is to limit the maximum work-in-process. By limiting the WIP-level production lead times should be kept constant. The major advantage is the improvement of the service level in combination with low inventories.

A continuous flow production with a broad product variety and especially with highly varying order sizes is regarded. Highly varying order sizes will also lead to a varying WIPlevel. In a worst case scenario the maximum WIP-level parameter unnecessarily prevents the release of a job order, leading to an adverse impact on the customer due dates.

In this special manufacturing environment it is suggested that no maximum WIP-level is set. Instead the operator has to release the appropriate amount of job orders to ensure that the first workstation (bottleneck) is always busy.

Further research needs to determine accurate guidelines for the operator to release the "right" amount of job orders for production. Additionally the implementation of CONWIP regarding the particular manufacturing environment as mentioned above will be described in a subsequent paper.

\section{REFERENCES}

Altendorfer, K.; Dickbauer, M.; Hübl, A.; Jodlbauer, H. \& Reitner, S. (2010). Leitfaden zur Einführung von CONWIP, Available from: http://tiny.cc/7yf5q/ Accessed: 2011-10-07

Altendorfer, K. \& Jodlbauer, H. (2007). CONWIP - hohe Liefertreue bei gleichzeitig niedrigen Beständen. PPSManagement, Vol. 12, No. 1, 2007, March, 16-19

Framinan, J.M.; Gonzalez, P.L. \& Ruiz-Usano, R. (2003). An overview of enterprise resource planning for intelligent enterprises. Production Planning \& Control, Vol. 14, No. 3, 2003, April-May, 255-265

Jodlbauer, H. \& Huber, A. (2008). Service-level performance of MRP, kanban, CONWIP and DBR due to parameter stability and environmental robustness. International Journal of Production Research, Vol. 46, No. 8, 2008, April, 2179-2195

Spearman, M.L.; Woodruff, D.L. \& Hopp, W.J. (1990). CONWIP: a pull alternative to kanban. International Journal of Production Research, Vol. 28, No. 5, 879-894 